Revista Eletrônica do Mestrado em Educação Ambiental

Programa de Pós-Graduação em Educação Ambiental

\title{
Alternativas para processos formativos de educação ambiental: a proposta da " (com) vivência pedagógica" diante de grandes e radicais desafios
}

\author{
Mauro Guimarães ${ }^{1}$ \\ Vicente Paulo dos Santos Pinto ${ }^{2}$
}

Resumo: A atual crise do capital materializada por inúmeros problemas socioambientais coloca inúmeros desafios para educação ambiental em todos os espaços da sociedade contemporânea. No que se refere a escola, esta conjuntura impõe a necessidade de se ir além da inserção da dimensão da temática ambiental numa perspectiva metodológica interdisciplinar. Para tanto, ressalta-se o papel de uma formação de educadores comprometidos, como militantes radicais da causa ambiental, como "sujeitos ecológicos" transformados e transformadores, dinamizadores de movimentos sociais contra hegemônicos em suas esferas de atuação. Diante disso, este artigo tem como objetivo central discutir possíveis alternativas da educação ambiental no contexto desses grandes desafios postos aos sistemas de ensino e à formação de professores no Brasil contemporâneo. Dá-se ênfase a proposta de articulação da "(Com)Vivência Pedagógica" com epistemologias que possam favorecer a formação de sujeitos dinamizadores de processos de transformação individual-coletiva da realidade em que vivemos.

Palavras-chave: educação ambiental; formação de professores; (com)vivência pedagógica.

\section{Alternatives for formative environmental education processes: the proposal of "pedagogical compatibility" beyond large and radical challenges}

\begin{abstract}
The current crisis of capital materialized by numerous socio-environmental problems poses numerous challenges for environmental education in all spaces of contemporary society. With regard to school, this situation imposes the need to go beyond the insertion of the dimension of the environmental theme in an interdisciplinary methodological perspective. For this, the role of a formation of committed educators, as radical militants of the environmental cause, as transformed and transforming "ecological subjects", is a role of social movements against hegemonic in their

\footnotetext{
${ }^{1}$ Departamento de Educação e Sociedade. Curso de Geografia e Pedagogia. Professor do Mestrado em Educação. E-mail: guimamauro@hotmail.com

${ }_{2}^{2}$ Possui graduação em Geografia pela UFJF (1987), mestrado em Geografia pela UFRJ (1997) e doutorado em Geografia pela UFRJ (2004). Professor Associado do Departamento de Geociências do Instituto de Ciências Humanas da UFJF. Email: vicente.pinto@ufjf.edu.br
}

Rev. Eletrônica Mestr. Educ. Ambient. Rio Grande, Edição especial XVI Encontro Paranaense de Educação Ambiental, p. 118-131, set. 2017. E-ISSN 1517-1256 
spheres of action. Therefore, this article has the main objective to discuss possible alternatives of environmental education in the context of these great challenges to the systems of education and teacher training in contemporary Brazil. Emphasis is given to the proposal of "Pedagogical Compatibility" with epistemologies that may favor the formation of subjects that are dynamic in the process of individual-collective transformation of the reality in which we live.

Keywords: environmental education; teacher training; pedagogical compatibility.

\section{Introdução}

Vivemos em um contexto - tanto na escala global, quanto na escala nacional - em que várias irracionalidades do capitalismo se explicitam em forma de crise e acirram as disputas entre projetos distintos para a sociedade em que vivemos. De um lado, a defesa da cidadania, da natureza, do trabalho, do público e da política na escola. De outro, a defesa do consumidor, do mercado, do capital, do privado e da "escola sem partido".

A crise do capital deve ser considerada endêmica e permanente, na qual o sistema encontra com seus próprios limites intrínsecos. Em seu caráter ambiental assistimos à "mercantilização da natureza por atacado" (HARVEY, 2004, p.123), explicitando-se a questão ambiental materializada por inúmeros problemas socioambientais decorrentes de múltiplas formas de incorporação da natureza a partir do seu valor econômico e da forma da distribuição da riqueza produzida. A destruição incontrolável dos bens naturais gera sérios problemas ambientais em escala globalizada: aquecimento da terra, desflorestamento, contaminação de rios e mares, desertificação, extinção de fauna e flora, perda da biodiversidade entre outros, colocando em risco a vida no planeta. As consequências ambientais provocadas pela demanda incontrolável de "recursos naturais" tende a materializar-se sob formas graves e num ritmo veloz (PINTO e ZACARIAS, 2009).

Em relação a um trabalho educativo, parte-se do pressuposto de que a grave degradação socioambiental contemporânea, que coloca em risco as condições ambientais de manutenção da vida, ou a chamada "crise ambiental”, é uma manifestação da lógica destrutiva do processo de produção e acumulação do capital em um crescimento ilimitado, que se realiza sobre a finitude de recursos naturais. É a manifestação da crise de um modelo de desenvolvimento que dá pistas da insustentabilidade socioambiental da sua reprodução; ou seja, uma crise civilizatória. A educação ambiental (EA), nessa perspectiva, tem um papel decisivo no sentido de contribuir para ampliar a consciência crítica dos indivíduos em sua atuação coletiva, para a necessidade de construção de uma nova ordem sociometabólica sustentável e de um saber ambiental. Isto significa uma opção por uma

Rev. Eletrônica Mestr. Educ. Ambient. Rio Grande, Edição especial XVI Encontro Paranaense de Educação Ambiental, p. 118-131, set. 2017. E-ISSN 1517-1256 
educação ambiental crítica, transformadora e emancipatória que vai além de "ensinar" bons comportamentos em relação à natureza e ao meio ambiente. É uma educação ambiental comprometida com as mudanças de valores e a transformação de indivíduos e sociedade.

Pensar a prática da educação ambiental num viés crítico na atualidade exige que discutamos esta prática considerando a escola como uma instituição social em disputa por atores associados a distintos projetos de sociedade, inserida em contexto socioambiental onde se imbricam os componentes da crise ambiental global refletidos nos problemas ambientais com base local. Escola, constituída em relação com sua comunidade, diante de uma diversidade de saberes e, ao mesmo tempo, diante de distintos (e na maioria das vezes, antagônicos e/ou descontextualizados) projetos políticos-pedagógicos.

Defendemos que a práxis de educação ambiental não deve ser neutra, nem geral, e, muito menos, homogênea. Faz-se num determinado contexto escolar, refletindo e condicionando práticas sociais e quem a realiza é um educador.

A abordagem crítica da educação ambiental compreende a crise ambiental como uma manifestação da lógica destrutiva do processo de produção e acumulação do capital; assim como da recíproca racionalidade, de uma intrínseca subjetividade inscrita no paradigma Disjuntivo (MORIN, 1999) da modernidade. As condições que levam à degradação socioambiental têm causas econômicas e políticas: sua gênese está ligada às relações sociais que se firmam entre os seres humanos a partir da maneira como se distribuem os meios de produção. Portanto, o enfrentamento dos problemas socioambientais resultantes do processo de produção exige uma proposta educativa que "discuta as relações no interior do processo produtivo, não apenas os seus efeitos" (FOLADORI, 2001, p.104).

O processo educativo é visto como um processo permanente, no qual indivíduos e comunidades tomam consciência das questões relativas ao ambiente e produzem conhecimentos, valores e atitudes que possam torná-los aptos a agir, individual e coletivamente, no sentido de buscar transformar as causas estruturais da crise ambiental. Isto implica uma opção por uma educação ambiental crítica, emancipatória, que vai além de "ensinar" bons comportamentos em relação à natureza e ao meio ambiente. É uma educação ambiental comprometida com as mudanças de valores e a transformação da sociedade. Para isso, não basta uma metodologia que traga a dimensão ambiental como uma temática transversal do currículo escolar, buscando uma abordagem interdisciplinar da discussão da problemática da realidade local e que essa tenha sido diagnosticada participativamente. Essa é uma boa metodologia pra inserir a dimensão ambiental na 
escola e favorável a criar um ambiente educativo receptivo a essa questão, porém requer educadores comprometidos, como militantes radicais (que vão a raiz) dessa causa, como "sujeitos ecológicos"3 (CARVALHO, 2012) transformados e transformadores, dinamizadores de movimentos sociais contra hegemônicos em suas esferas de atuação.

Portanto, o enfrentamento da crise ambiental exige um processo educativo amplo, enraizado em todos os setores sociais. Exige reafirmarmos a educação ambiental, antes de tudo, como educação. Como afirma Guimarães (2004, p. 138), "educação é construção e não apenas reprodução e transmissão de conhecimentos, é a construção de novos caminhos, de novas relações entre a sociedade e a natureza".

Considerando estes pressupostos este artigo tem como objetivo central discutir possíveis alternativas da educação ambiental no contexto dos grandes desafios postos aos sistemas de ensino e formação de professores no Brasil contemporâneo. Principalmente porque se defende que entre os grandes desafios está a necessidade de uma radicalidade na formação desses educadores.

Inicialmente, são estabelecidas algumas considerações gerais acerca do Sistema Nacional de Educação e a formação de professores dando ênfase à educação ambiental. A seguir, diante da gravidade da crise socioambiental e considerando necessidade da radicalidade na formação de educadores ambientais nos propusemos a pensar a "(Com)Vivência Pedagógica"4 com outras epistemologias, para além da hegemônica na modernidade, que possam favorecer a formação de sujeitos dinamizadores de processos de transformação individual-coletiva da realidade em que vivemos. No encerramento do texto tecemos nossas considerações finais.

\section{Considerações acerca das relações entre as políticas públicas, a formação de professores e o campo da educação ambiental}

O Brasil vive um momento de grandes disputas entre dois projetos distintos de governança: um resultante do sufrágio universal de 2014, que se assenta na valorização do Estado Nacional e na busca da garantia dos direitos sociais do povo brasileiro; e outro,

\footnotetext{
3 "O sujeito ecológico demarca um campo de ideais disponíveis para a formação identitária do jovem que ingressa na esfera pública e que partilha, em algum nível, de um projeto político emancipatório. A ideia de mudanças radicais cultivada pelo ideário ecológico abarca não apenas uma nova sociedade, mas também um novo sujeito que se vê como parte desta mudança e a compreende como uma revolução de corpo e alma, ou seja, uma reconstrução do mundo, incluindo os estilos de vida pessoal."

${ }^{4}$ Denominamos "(Com)Vivência Pedagógica" para evidenciar um processo formativo que busque na intensa vivência com outras epistemologias, demarcadas por outros modos de vida que tenham como centralidade o convívio dialógico entre indivíduos, sociedade e natureza. Em nosso Grupo de pesquisa (GEPEADS/UFRRJ) temos trabalhado na convivência principalmente com povos indígenas, mas também quilombolas e comunidades alternativas.
}

Rev. Eletrônica Mestr. Educ. Ambient. Rio Grande, Edição especial XVI Encontro Paranaense de Educação Ambiental, p. 118-131, set. 2017. E-ISSN 1517-1256 
resultado de uma manobra parlamentar engendrado por poderosos interesses corporativos do grande capital, defendidos pelas grandes corporações midiáticas e formalizado pelo poder judiciário, que quer impor reformas neoliberais que favorecem os agentes globais do capitalismo. Dentre as grandes discussões nacionais no bojo destas disputas se coloca a questão das políticas e gestões da educação nacional. E no centro desta questão emerge a implantação do Plano Nacional de Educação (PNE), recentemente aprovado, que traça metas e diretrizes para a Educação brasileira e sugere mecanismos de cooperação institucional para viabilizar a melhoria da Educação. A Lei n ${ }^{\circ} 13.005 / 2014$ que aprovou o PNE define que "os estados, o Distrito Federal e os municípios deverão elaborar seus correspondentes planos de Educação ou adequar os planos já aprovados em lei, em consonância com as diretrizes, metas e estratégias previstas no PNE”. Advindos deste processo institucional, muitos desafios devem ser enfrentados para que possamos construir tal sistema.

Apesar dos avanços realizados em termos das políticas públicas para a Educação desde a Constituição Nacional de 1988 podemos constatar, através dos movimentos recentes no campo da educação brasileira, que continuamos diante de uma realidade em que ainda falta alguma coisa. Não obtivemos ainda um sistema eficaz, capaz de salvaguardar a oferta de educação de qualidade de forma universal.

Segundo Lima (2015), a Constituição brasileira definiu que é possível fazer uma educação de qualidade de forma descentralizada em sua execução, porém falta elaborar uma legislação que estabeleça e esclareça, de uma vez por todas, as relações entre os entes federados, definindo as responsabilidades de cada participante. Para o mesmo, faz-se necessário ampliar os espaços de decisão, com a criação de fóruns federativos mais amplos que considerem o protagonismo dos estados.

A participação popular deve ser ampliada para além da participação nos conselhos escolares. Todo processo deve ser feito de forma democrática, com o máximo de participação da sociedade e tendo em vista que o esclarecimento dos objetivos e princípios da Educação que queremos para o nosso País configura o grande elo de ligação do sistema. Já sabemos, a partir da LDB e das Diretrizes Curriculares, que seja o Sistema Nacional de Educação construído pela via da celebração de um grande pacto ou mediante a aprovação de lei específica, ele deve ser capaz de prover: a) a ampliação da Educação obrigatória; b) a definição e a garantia de padrões mínimos de qualidade, incluindo a igualdade de condições para acesso e permanência na escola; c) a implementação de sistema nacional de avaliação da Educação Básica e superior voltado para subsidiar o processo de gestão educativa e para garantir a melhoria da aprendizagem e dos processos formativos; d) a existência de programas suplementares e

Rev. Eletrônica Mestr. Educ. Ambient. Rio Grande, Edição especial XVI Encontro Paranaense de Educação Ambiental, p. 118-131, set. 2017. E-ISSN 1517-1256 
de apoio pedagógico, de acordo com as especificidades de cada nível, etapa e modalidades de Educação; e) a garantia de instalações gerais adequadas aos padrões mínimos de qualidade; f) ambiente adequado à realização de atividades de ensino, pesquisa, extensão, lazer e recreação, práticas desportivas e culturais, reuniões com a comunidade; g) biblioteca com espaço físico apropriado para leitura, consulta ao acervo, estudos individuais e/ou em grupo; h) condições de acessibilidade e atendimento para pessoas com deficiência; i) disponibilidade de docentes para todas as atividades curriculares e de formação. (LIMA, 2015, p.26)

Trazendo a discussão mais especificamente para o campo da educação ambiental, Sorrentino e Portugal (s/d), colocam o desafio da construção de uma Base Nacional Comum Curricular (BNCC) que estabeleça um tema integrador comprometido com a Educação Ambiental (EA), se perguntam sobre as possiblidades de construção deste documento considerando os princípios, objetivos e as diretrizes já enunciados em documentos como o Tratado de Educação Ambiental para Sociedades Sustentáveis e Responsabilidade Global (1992), a Carta da Terra (2000), o Programa Nacional de Educação Ambiental - ProNEA, que não consta nos PPA 2012/2015 e 2016/2019, mas permanece como o Programa formulado participativamente pelo Órgão Gestor da Política Nacional de Educação Ambiental - PNEA (1999) e no seu Decreto regulamentador (2002), todos contemplados nas Diretrizes Curriculares Nacionais para a Educação Ambiental DCNEA (2012).

Porém, após a divulgação oficial pelo Ministério da Educação, no final de janeiro de 2017, da terceira versão da BNCC (2017) o que até então vem se configurando é a gestação de três unidades temáticas propostas para orientar a elaboração dos currículos de Ciências, "que se repetem ao longo de todo Ensino Fundamental" (p. 277). O referido documento preconiza que as aprendizagens essenciais a ser asseguradas neste componente curricular foram organizadas em "Matéria e energia", "Vida e evolução" e "Terra e Universo". Nesta versão da base essas três unidades temáticas devem estar integradas, segundo o que propõe o documento, em "temas importantes", tais como, "a sustentabilidade socioambiental, o ambiente, a saúde e a tecnologia”. Não há a explicitação de EA como tema gerador, o que retira da nova BNCC todo o processo historicamente construído em torno dos princípios, objetivos e diretrizes da educação ambiental como centralidade.

Para Sorrentino (2013), a perspectiva educadora ambientalista possibilita aprendizados sobre economia solidária, economia local, consumismo, sustentabilidade socioambiental, desenvolvimento sustentável e sociedades sustentáveis, bem como o 
questionamento de necessidades materiais simbólicas e o aprendizado de valores, conceitos e práticas como os de participação, pertencimento, comunidade, identidade, potência de agir, diálogo e felicidade.

A "Base" dá ênfase a uma "educação científica contemporânea", salienta "os múltiplos papéis desempenhados pela relação ciência-tecnologia-sociedade na vida moderna e na vida do planeta Terra como elementos centrais no posicionamento e tomada de decisões frente aos desafios éticos, culturais, políticos e socioambientais" BNCC (2017, p. 281).

A BNCC é uma política pública de Estado e, portanto, reúne um conjunto de atores individuais e coletivos. Uma ação política fundamental de "algo comum" é a criação de arenas decisórias ampliadas para as políticas educacionais e, dentro delas, o currículo. Daí ressaltamos a necessidade de resgatar a educação ambiental como um tema integrador respaldado em marcos legais estruturantes para ser eixo transversal (Constituição Federal art. 225 e as Leis que instituem a Política Nacional de Meio Ambiente e a Política Nacional de Educação Ambiental, dentre outras).

Na tradição e na legislação de praticamente todos os países da América Latina consolidou-se o termo EA e, mesmo antes, durante e após a Rio92, quando o sistema das Nações Unidas buscou difundir o conceito de educação para o desenvolvimento sustentável (ou mesmo educação para a sustentabilidade ou sustentabilidade socioambiental), ele foi mantido majoritariamente na literatura especializada, na legislação e no cotidiano escolar e das ações comunitárias, após longos e profundos diálogos sobre os sentidos dos diversos termos. Sorrentino e Portugal (s/d)

Neste quadro político que estabelece uma ruptura da EA como política nacional de educação, reforça, a nosso ver, a tendência já identificada por várias pesquisas de um processo de inserção fragmentada da educação ambiental na escola. No bojo de um governo sem respaldo popular, engendrado por uma manobra parlamentar de legitimidade questionável, verifica-se a reprodução de um modelo neoliberal que quer impor um currículo que tende a reforçar uma formação de professores centrada na racionalidade técnica. Prioriza-se as competências técnicas para a execução de metas e objetivos, baseados na "relação ciência-tecnologia-sociedade na vida moderna e na vida do planeta Terra como elementos centrais no posicionamento e tomada de decisões frente aos desafios éticos, culturais, políticos e socioambientais.” BNCC (2017, p. 281).

Como aponta Teixeira e Tozzoni-Reis (2013), a partir desta concepção estritamente técnica, o professor cumpre metas, atinge objetivos, alcança índices pré-estabelecidos e 
entre outros atributos se transforma em um executor de tarefas [...] esse processo de (des)qualificação dos professores reflete diretamente em sua preparação - ou não - para lidar com temas recentes que se apresentam na escola, uma vez que esta instituição é sempre alvo de proposições relacionadas aos problemas da sociedade, por exemplo a educação ambiental, a educação para cidadania, educação sexual entre outros temas.

Verificamos, a despeito de sua formação fragmentada e de abordagem técnico-instrumental, a responsabilização da escola e do professor no sentido de dar respostas a essas temáticas que imputam, numa visão redentora da educação e da escola, funções de resolver problemas gerados pelo modo de produção vigente, sem sequer prepará-los para compreendê-los. Tudo isso contribui para aumentar a confusão entre o que é "o que fazer" do professor: organizar a apropriação dos conhecimentos produzidos socialmente e acumulados historicamente pelo gênero humano aos sujeitos singulares ou ensinar a resolver problemas de forma prática e utilitária para satisfazer ou se adequar à totalidade da sociedade capitalista? (TEIXEIRA E TOZZONI-REIS, 2013, p.13)

No cenário político brasileiro há um forte embate por diferentes projetos de sociedade; um liberal, vinculado aos interesses do grande capital causador da grave crise ambiental da atualidade; outro que se coaduna aos interesses populares de emancipação e transformação de uma realidade degradada e desigual. Quando políticas públicas de Educação Ambiental que vinham sendo consolidadas, tendendo para uma perspectiva crítica, estão sendo ameaçadas por esse novo contexto político conservador, se faz mister refletir sobre o grande desafio que se coloca na atuação do professor/educador. Desafio que coloca o embate por uma "escola sem partido", ameaçando a autonomia docente, a liberdade e a diversidade de ideias. Que educador formar e como formar diante de tão grande desafio?

Guimarães e Medeiros (2016, p.52), nos alertam que o educador, apesar de bem intencionado, pode se manter alienado. Defendem que não haja uma aceitação do discurso dominante por parte dele (professor), mas ao reproduzir (inconscientemente) a forma hegemônica de ver o mundo, não se produz um tensionamento por uma prática diversa e, assim, a prática resultante, é reprodutivista na constituição do real. Propõem que "para ruptura dessa armadilha paradigmática é necessário provocar, pela práxis pedagógica, o estranhamento da visão dominante pela reflexão crítica que se fertiliza na prática conjunta diferenciada (fundamentalmente no coletivo) e que promove condições concretas e simbólicas novas que permitem a percepção e vivência de uma experiência pedagógica diferenciada". 


\section{A “(Com)Vivência Pedagógica" como proposta radical para a formação de educadores ambientais}

$\mathrm{Na}$ sociedade contemporânea brasileira hegemonicamente podemos afirmar que esse referido professor não é o educador ambiental que temos resultante das formações iniciais, já que ainda hoje é incipiente a inserção da dimensão ambiental nos cursos de formação de professores. Ainda mais diante da aniquilação das políticas públicas de formação de educadores ambientais que vinham sendo implantadas.

Pela gravidade e urgência da questão ambiental, a formação de professores/educadores ambientais mostra-se fundamental e precisa ser assumida como ato de resistência por quem já milita nesta causa - pesquisadores e educadores. Mas num momento de recuo das políticas públicas afeitas a essa vertente mais crítica de Educação Ambiental, a atuação de grupos de pesquisa, de redes de educadores, de diversas iniciativas formativas, poderão se voltar para uma intervenção em uma escala micro política da radicalidade da formação de sujeitos ecológicos.

A radicalidade da formação para resultar em um educador liberto dos grilhões de uma visão ingênua de práticas conservadoras, presos a armadilha paradigmática. Capaz de se colocar como um dinamizador de movimentos contra hegemônicos, que potencialize processos de transformação da grave realidade de degradação socioambiental, esse é o educador que pretendemos resultado de um processo formativo de Educação Ambiental crítica. O professor/educador ambiental que por sua práxis educadora se constitua como um mobilizador de sujeitos coletivos que se colocam a resistir e emergir práticas diferenciadas no cotidiano escolar, semeadores de movimentos de germinação da transição paradigmática.

Acreditamos que a formação radical de educadores ambientais como sujeitos ecológicos, militantes e com um compromisso vital com a causa ambiental, são nós fundamentais de uma rede que emerge contra hegemonicamente, constituídas por novas relações horizontalizadas que convergem em um movimento de transição paradigmática, na qual os educadores ambientais se constituem como dinamizadores.

Como Grupo de Estudos e Pesquisa inseridos na Universidade Pública, comprometidos com a perspectiva crítica, transformadora e emancipatória da EA, estamos buscando desenvolver processos formativos de educadores ambientais, que acreditamos radicais, voltando-nos a essa atuação micro política.

Propomos a formação de grupos de educadores ambientais, que, por meio de processos intensos de imersão, experenciem pelo menos três princípios formativos: a 
indignação ética, a reflexão crítica e a postura dialógica. Estamos convictos que essa formação intensiva se dá em ambientes educativos propícios a rupturas com os referenciais disjuntivos e de simplificação dos paradigmas da modernidade. Sejam em ambientes em que possamos vivenciar a ruptura do dualismo dicotômico, que leva os indivíduos a um distanciamento/estranhamento da natureza; seja por romper com o padrão relacional da modernidade que hierarquiza para dominar e explorar. Nesse ambiente potencializamos o exercício de novas relações de um com o outro, na relação dialógica entre indivíduos e destes com a natureza. A vivência de reconstrução do sentimento de pertencimento a um todo, como sujeitos coletivos e como natureza que somos. Acreditamos que movidos por uma indignação ética da degradação humana e da natureza, na convivência intensa de compreendermos, por uma reflexão crítica, e vivermos outras relações que nos conecte, possamos nos colocar como indivíduos num caminho conjunto de educadores-educandos, rumando para um reencontro com o natural na formação de sujeitos ecológicos transformados e transformadores em suas práxis pedagógicas.

Como forma de aprofundar essa experiência em uma práxis de ruptura com a "armadilha paradigmática", que nos aprisiona em uma visão ingênua e práticas conservadoras ancoradas inconscientemente nos paradigmas da modernidade, propomos processos formativos em imersões em outros modos de vida, referenciados por outras epistemologias, em um exercício de "interculturalidade crítica"5 (WALSH, 2010) em “(Com)Vivência Pedagógica”. Nesse processo, nos desestruturamos no sentido existencial de ruptura com uma visão de mundo hegemônica, para nos reconstruirmos em um nível ampliado de consciência. Uma consciência crítica, mais afeita a complexidade da realidade com seus antagonismos, concorrências e complementaridades, com uma postura conectiva e amorosa que abriga o diverso e o uno.

Acreditamos que essa seja uma importante possibilidade de intervenção política e um compromisso viável de diferentes grupos e experiências educativas em curso, que devem buscar com uma intencionalidade educomunicativa estabelecer redes de saberes e fazeres compartilhados, que venham como práticas contra hegemônicas engrossar e consolidar os processos de enfrentamento e transformação da realidade de uma grave crise ambiental que vivemos na atualidade.

\footnotetext{
5 “[...] se entende como uma estratégia, ação e processo permanentes de relação e negociação, em condições de respeito, legitimidade, simetria, equidade e igualdade. Porém, ainda mais importantes, é seu entendimento, construção e posicionamento como projeto político, social, ético e epistémico - de saberes e conhecimentos-, que afirma a necessidade de mudar não só as relações, mas também as estruturas, condições e dispositivos de poder que mantêm a desigualdade, inferiorização, racialização e discriminação."
}

Rev. Eletrônica Mestr. Educ. Ambient. Rio Grande, Edição especial XVI Encontro Paranaense de Educação Ambiental, p. 118-131, set. 2017. E-ISSN 1517-1256 
Para isso, como grupo de pesquisa temos buscado conhecer outras epistemologias, a partir do referencial da Educação Ambiental crítica, das teorias da complexidade e estudos sobre decolonialidade, junto aos povos originais no Brasil, como os Krahô e Guarani, comunidades Quilombola, e os Quéchua andinos. Como também em epistemologias em construção, como de comunidades alternativas de cunho religiosofilosóficos e de movimentos de formação de redes de produção-consumo diferenciados.

Sobre essa última linha de pesquisa, de movimentos de formação de redes de produção-consumo diferenciados, apresentamos por exemplo algumas ideias prévias que estamos pesquisando, como iniciativas que apontam para uma "racionalidade ambiental" (LEFF, 2003) em construção, que pretendemos ilustrar indícios de sua inserção na formação de educadores ambientais.

Consideramos que esses indícios podem vir de uma proposta de produção agroecológica, engendrada por um movimento social que tem como parte professores/educadores inseridos em processos formais e não formais de educação ambiental, sejam esses desenvolvidos em escolas, universidades, ONGs, órgãos extensionistas.

Através de técnicas agrícolas que integram os ecossistemas locais, muitos agricultores e agricultoras tiram o sustento de suas famílias, comercializando sua produção em comércios locais, supermercados, abastecendo programas de governo (como o Programa de Aquisição de Alimentos e a Merenda Escolar) e, principalmente, vendendo em feiras de rua.

As feiras orgânicas e agroecológicas têm se multiplicado e ganhado força em todo o território nacional. Nelas, o produtor pode ter contato direto com o consumidor e com outros produtores, trocando informações e ajudando a divulgar seu trabalho. Estimular a formação de feiras e centros de distribuição de produtos agroecológicos é estimular um modelo agrícola sustentável, que garante soberania alimentar, justiça social e o cuidado com os ecossistemas.

Para além de atividade produtiva e movimento social, a agroecologia constitui-se em um modo de vida que se estrutura considerando a morada, o campo, as feiras, os cursos, os encontros e as reuniões como espaços-tempos para a formação coletiva, verdadeiros ambientes educativos.

Temos acompanhado, em Juiz de Fora/MG, o movimento MOGICO, que envolve uma rede de produção e consumo de produtos orgânicos e artesanais - um coletivo que tem sua origem na Paineira Escola Waldorf, que busca se organizar para criar possibilidade de 
realizar um modo de vida alternativa. A vivência do processo de constituição desse movimento promove o trabalho como um princípio educativo, estabelece relações dialógicas entre os participantes, o reforço recíproco pela viabilização de um modo de vida baseado em princípios mais integrativos e saudáveis na relação com a natureza, que prima pela sustentabilidade socioambiental. A vivência conjunta dessa realidade se mostra muito pedagógica.

Acreditamos e pretendemos construir indicativos, para os nossos objetivos de Educação Ambiental, da pertinência de ambientes educativos de imersão experiencial, em que grupos de educadores ambientais em formação, possam vivenciar criticamente juntos um cotidiano estabelecido por outra racionalidade produtiva, sob outros valores sociais, em que perspectivas integradoras e coletivistas sejam valores centrais do seu modo de organização social. Temos como hipótese, que a convivência pedagógica nestes ambientes educativos, possa propiciar experiências de formação de professores que permitem a ruptura, entre outros, do pensamento dualista dicotômico estruturante dos indivíduos modernos, quando aliadas a vivências de práticas individuais e coletivas baseadas em outros padrões relacionais e em uma outra racionalidade ambiental. Nesse ambiente buscase romper, num processo convivencial, com as estruturas dominantes de pensamento da sociedade moderna, experienciando a diversidade de formas de ler, compreender e estar no mundo.

\section{Considerações Finais}

Nessa linha de pesquisa que estamos investindo esforços na grave conjuntura da atualidade. A criação de ambientes educativos para a formação de educadores ambientais, em que imerso em relações intensas e conjuntas, vivenciando outras referências epistemológicas, possa possibilitar a indivíduos em relações, se constituir como um sujeito ecológico.

Entendemos que é esse educador ambiental em suas inserções na sua realidade cotidiana, como dinamizador de movimentos contra hegemônicos, articulador de redes que se constituem em espaços públicos, em que o diferente ao caminho único hegemônico emerge; é esse um semeador do novo. Acreditamos que isso é um grande desafio colocado para cada um de nós, que nos identificamos como educador ambiental: contribuirmos na criação de ambientes educativos em que a radicalidade de uma outra existência e um outro mundo esteja em germinação. 


\section{Agradecimentos}

Agradecemos à Coordenação de Aperfeiçoamento de Pessoal de Nível Superior (CAPES) pela concessão da bolsa de pós-doutoramento no âmbito do Programa Nacional de Pós-Doutorado (PNPD) que permitiu o desenvolvimento do estágio supervisionado no Programa de Pós-Graduação Stricto Sensu em Educação, Contextos Contemporâneos e Demandas Populares (PPGEduc) da Universidade Federal Rural do Rio de Janeiro (UFRRJ) possibilitando a parceria que resultou na realização deste artigo.

\section{Referências}

CARVALHO, I. de M. http://www.ondajovem.com.br/acervo/7/o-sujeito-ecologico. Edição 7, março de 2012.

FOLADORI, G. Limites do desenvolvimento sustentável. Campinas: Editora da Unicamp, São Paulo: Imprensa oficial, 2001.

GUIMARÃES, M. A formação de educadores ambientais. $4^{\text {a }}$ edição. Campinas, SP: Papirus, 2004.

GUIMARÃES, M. e MEDEIROS, H. Outras epistemologias em educação ambiental: o que aprender com os saberes tradicionais dos povos indígenas. Rev. Eletrônica Mestrado em Educação Ambiental. Ed. Especial, julho/2016. Disponível em: https://www.seer.furg.br/remea/article/view/5959. Acessado em 30 de abril de 2017.

HARVEY, D. O novo imperialismo. São Paulo: Loyola, 2004.

LEFF, E. (org.) . A Complexidade Ambiental. Blumenau: Cortez/Edifurb, 2003.

LIMA, J. F. Sobre a instituição do Sistema Nacional de Educação. In: ALVES, L. R.; RONCA, A. C. C. (orgs.) O Plano Nacional de Educação e o Sistema Nacional de Educação: educar para a equidade. São Paulo: Fundação Santillana, 2015. p.19-31

MORIN, E. Ciência com Consciência. Rio de Janeiro: Bertrand, 1999.

PINTO, V. P. S. e ZACARIAS, R. Crise ambiental: adaptar ou transformar? As diferentes concepções de educação ambiental diante deste dilema. Educação em Foco. no 14 volume 02 , setembro/2009.

SORREnTINO, M. (org.). Educação Ambiental e Políticas Públicas: conceitos, fundamentos e vivências. Curitiba: Appris, 2013.

\section{SORRENTINO M. e PORTUGAL S. Educação Ambiental e a Base Nacional Comum} Curricular. Disponível em: http://megaslides.org/doc/607292/educa\%C3\%A7\%C3\%A3o-ambiental-e-a-basenacional-comum-curricular-marcos. (s/d). Acessado em 29 de abril de 2017.

TEIXEIRA, L. A. e TOZONI-REIS, M. F. de C. A educação ambiental e a formação de professores: pensando a inserção da educação ambiental na escola pública. Rio Claro:

Anais VII EPEA - Encontro Pesquisa em Educação Ambiental, julho/2013. Disponível em: http://www.epea.tmp.br/epea2013_anais/plenary/. Acessado em 29 de abril de 2017.

Rev. Eletrônica Mestr. Educ. Ambient. Rio Grande, Edição especial XVI Encontro Paranaense de Educação Ambiental, p. 118-131, set. 2017. E-ISSN 1517-1256 
WALSH, C. Interculturalidade crítica e educação intercultural.

https://docs.google.com/document/d/1GLTsUp2CjT5zIj1v5PWtJtbU4PngWZ4H1UUkNc4

LIdA/mobilebasic. 2010.

Submetido em: 31-07-2017.

Publicado em: 30-09-2017.

Rev. Eletrônica Mestr. Educ. Ambient. Rio Grande, Edição especial XVI Encontro Paranaense de Educação Ambiental, p. 118-131, set. 2017. E-ISSN 1517-1256 